\title{
Decreased adipose tissue oxygenation associates with insulin resistance in individuals with obesity
}

\author{
Vincenza Cifarelli, ${ }^{1}$ Scott C. Beeman, ${ }^{1,2}$ Gordon I. Smith, ${ }^{1}$ Jun Yoshino, ${ }^{1}$ Darya Morozov, ${ }^{2}$ Joseph W. Beals, ${ }^{1}$ Brandon D. Kayser, ${ }^{1}$ \\ Jeramie D. Watrous, ${ }^{3}$ Mohit Jain, ${ }^{3}$ Bruce W. Patterson, ${ }^{1}$ and Samuel Klein ${ }^{1}$ \\ ${ }^{1}$ Center for Human Nutrition and Atkins Center of Excellence in Obesity Medicine, and 2Mallinckrodt Institute of Radiology, Washington University School of Medicine, St. Louis, Missouri, USA. \\ ${ }^{3}$ Departments of Medicine and Pharmacology, University of California, San Diego, La Jolla, California, USA.
}

\begin{abstract}
BACKGROUND. Data from studies conducted in rodent models have shown that decreased adipose tissue (AT) oxygenation is involved in the pathogenesis of obesity-induced insulin resistance. Here, we evaluated the potential influence of AT oxygenation on AT biology and insulin sensitivity in people.
\end{abstract}

METHODS. We evaluated subcutaneous AT oxygen partial pressure $\left(\mathrm{pO}_{2}\right)$; liver and whole-body insulin sensitivity; AT expression of genes and pathways involved in inflammation, fibrosis, and branched-chain amino acid (BCAA) catabolism; systemic markers of inflammation; and plasma BCAA concentrations, in 3 groups of participants that were rigorously stratified by adiposity and insulin sensitivity: metabolically healthy lean (MHL; $\boldsymbol{n}=11$ ), metabolically healthy obese (MHO; $n=15)$, and metabolically unhealthy obese (MUO; $n=20$ ).

RESULTS. AT $\mathrm{pO}_{2}$ progressively declined from the MHL to the $\mathrm{MHO}$ to the $\mathrm{MUO}$ group, and was positively associated with hepatic and whole-body insulin sensitivity. $A T \mathrm{pO}_{2}$ was positively associated with the expression of genes involved in BCAA catabolism, in conjunction with an inverse relationship between $\mathrm{AT} \mathrm{pO}_{2}$ and plasma $\mathrm{BCAA}$ concentrations. AT $\mathrm{pO}_{2}$ was negatively associated with AT gene expression of markers of inflammation and fibrosis. Plasma PAI-1 increased from the $\mathrm{MHL}$ to the $\mathrm{MHO}$ to the $\mathrm{MUO}$ group and was negatively correlated with $\mathrm{AT} \mathrm{pO}_{2}$, whereas the plasma concentrations of other cytokines and chemokines were not different among the MHL and MUO groups.

CONCLUSION. These results support the notion that reduced AT oxygenation in individuals with obesity contributes to insulin resistance by increasing plasma PAI-1 concentrations and decreasing AT BCAA catabolism and thereby increasing plasma BCAA concentrations.

TRIAL REGISTRATION. ClinicalTrials.gov NCT02706262.

FUNDING. This study was supported by NIH grants K01DK109119, T32HL130357, K01DK116917, R01ES027595, P42ES010337, DK56341 (Nutrition Obesity Research Center), DK20579 (Diabetes Research Center), DK052574 (Digestive Disease Research Center), and UL1TR002345 (Clinical and Translational Science Award); NIH Shared Instrumentation Grants S10RR0227552, S100D020025, and S100D026929; and the Foundation for Barnes-Jewish Hospital.

\section{Introduction}

Insulin-resistant glucose metabolism is the most common metabolic abnormality associated with obesity, and is an important risk factor for type 2 diabetes and cardiovascular disease (1). Although insulin sensitivity generally declines with increasing adiposity, there is considerable heterogeneity in the severity of insulin resistance at any given value for body mass index (BMI) (2); in fact, some people with obesity are even considered to be metabolically healthy with normal insulin sensitivity (3). It is possible that

Authorship note: VC and SCB contributed equally to this work.

Conflict of interest: SK has received grants from Janssen Pharmaceuticals, personal fees from Pfizer, and personal fees from Merck Sharp \& Dohme Corp.

Copyright: () 2020, American Society for Clinical Investigation.

Submitted: June 30, 2020; Accepted: August 26, 2020; Published: November 9, 2020

Reference information: / Clin Invest. 2020;130(12):6688-6699.

https://doi.org/10.1172/JCl141828. differences in adipose tissue (AT) oxygenation contribute to the variability in insulin resistance. Studies conducted in rodent models have shown that the expansion of AT mass without adequate neovascularization can cause AT hypoxia, leading to AT inflammation and fibrosis, and systemic insulin resistance (4), whereas increasing AT oxygen content decreases AT inflammation and fibrosis and increases whole-body insulin sensitivity in obese mice (5). The link between alterations in AT biology and systemic insulin action suggests a communication between AT and other organs. The systemic signaling mechanism could be related to increased plasma concentrations of proinflammatory cytokines and chemokines secreted by AT immune cells (6), increased plasma branched-chain amino acids (BCAAs) caused by decreased AT BCAA oxidative metabolism (7-11), or both.

The effect of excess adiposity on AT oxygenation in people is unclear because of conflicting data from different studies that have reported that AT partial pressure of oxygen $\left(\mathrm{pO}_{2}\right)$ was lower 


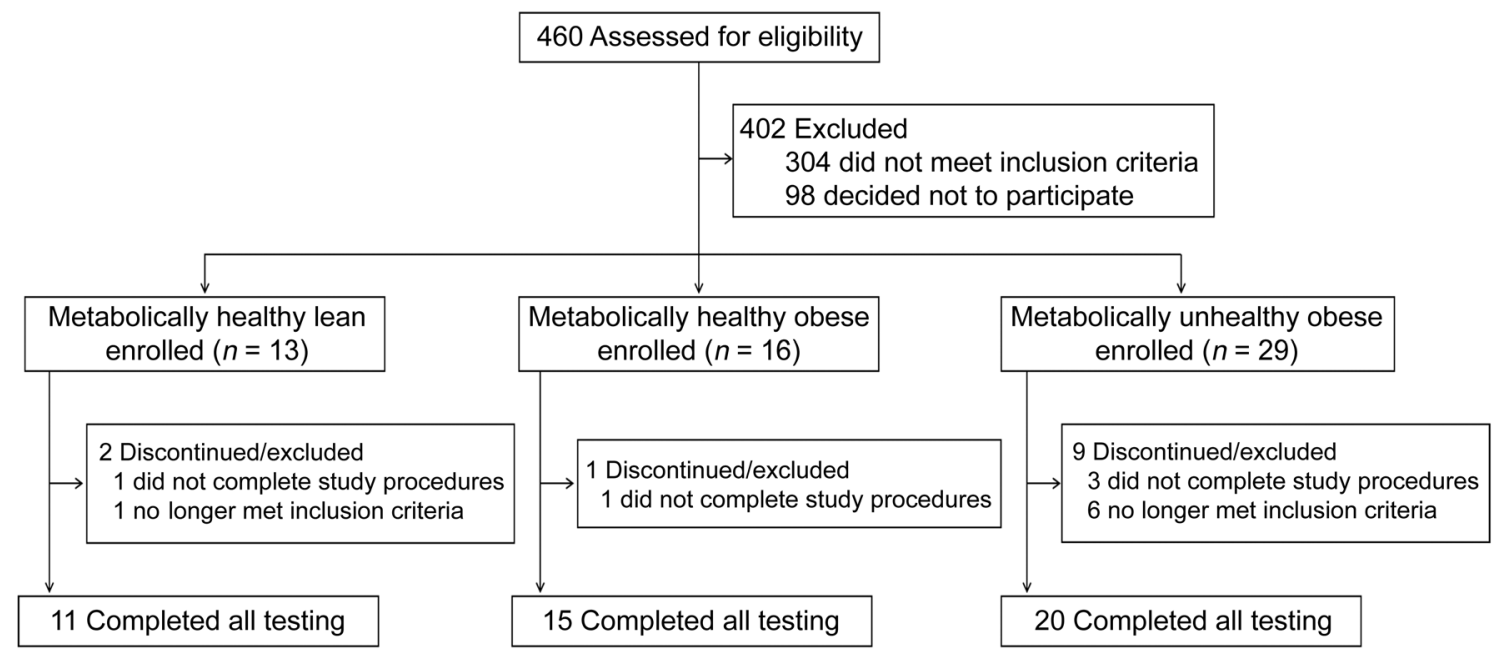

Figure 1. Flow diagram of study participants.

$(5,12-15)$ or not different $(16,17)$ in people with obesity than in people who are lean, and that $\mathrm{AT} \mathrm{pO}_{2}$ was higher (5), lower (17), or not different $(13,14)$ in people with metabolically healthy obesity $(\mathrm{MHO})$ than in those with metabolically unhealthy obesity

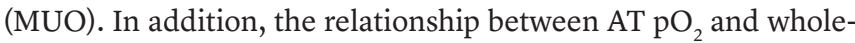
body insulin sensitivity in people is unclear because of conflicting data from different studies that reported $\mathrm{AT}_{\mathrm{O}_{2}}$ was inversely (16, $17)$ or not associated $(12,14)$ with insulin sensitivity. The reason for the differences between studies could be related to differences in the methods used to assess AT oxygen content, inadequate numbers of participants needed to detect statistically significant effects, and differences in the criteria used to define insulin-resistant and insulin-sensitive cohorts.

The purpose of the present study was to evaluate the potential impact of AT oxygenation on insulin sensitivity; on AT biology (markers of inflammation, fibrosis, and BCAA catabolism); and on systemic markers of inflammation and plasma BCAA concentrations in 3 distinct groups of participants, rigorously characterized as metabolically healthy lean (MHL), MHO, or MUO based on BMI, insulin sensitivity, plasma triglyceride (TG) concentration, and intrahepatic TG (IHTG) content. We hypothesized that AT $\mathrm{pO}_{2}$ would (a) progressively decline from the MHL to the MHO to the MUO group; (b) correlate positively with hepatic and wholebody insulin sensitivity; (c) correlate negatively with AT markers of inflammation and fibrosis and negatively with plasma markers of inflammation; and (d) correlate positively with AT markers of BCAA catabolism and negatively with plasma BCAA concentrations.

\section{Results}

Subject flow, body composition, and metabolic characteristics. Among the 58 participants who enrolled in the study, 46 completed the study testing procedures (MHL $n=11$, MHO $n=15$, and MUO $n=20$; Figure 1). The MHO and MUO groups were purposely matched on BMI and percentage body fat. There was no difference in subcutaneous abdominal adipose tissue (SAAT) volume between these 2 groups, but intra-abdominal adipose tissue (IAAT) volume and IHTG content were greater in the MUO than in the MHO group (Table 1). By design, IHTG content was similar in the MHO and MHL groups; however, IAAT volume was greater in the MHO than in the MHL group. Average adipocyte size in the MUO group was not different from that in the MHO group, but adipocyte size was larger in both the MHO and MUO groups than in the MHL group. Fasting plasma TG and glucose concentrations, hemoglobin $\mathrm{A}_{1 \mathrm{c}}$, and 2-hour oral glucose tolerance test (OGTT) plasma glucose concentration were greater in the MUO than in the MHO and MHL groups, with no difference between the MHO and MHL groups. Plasma insulin and the homeostasis model assessment of insulin resistance (HOMA-IR) progressively increased from the MHL to the MHO to the MUO group, whereas plasma HDL-cholesterol, hepatic insulin sensitivity index (HISI) assessed as the reciprocal of the product of basal endogenous glucose production rate and basal plasma insulin concentration, and wholebody insulin sensitivity assessed as the glucose rate of disposal relative to plasma insulin concentration (glucose $\mathrm{Rd} / \mathrm{I}$ ) during a hyperinsulinemic-euglycemic clamp procedure progressively decreased from the MHL to the MHO to the MUO group (Table 1). Participants in the MUO group were about 8 years older than participants in the MHL group. However, including participant age as a covariate in our statistical analyses did not change the statistical significance of any of our outcomes or alter any conclusions.

AT oxygen tension and HIF1A gene expression are affected by adiposity and positively associated with insulin sensitivity. $\mathrm{AT} \mathrm{pO}_{2}$ decreased progressively from the MHL $(64.7 \pm 3.6 \mathrm{mmHg})$ to the MHO $(56.7 \pm 2.8 \mathrm{mmHg}$ ) to the MUO group $(48.6 \pm 1.9 \mathrm{mmHg}$ ) (Figure $2 \mathrm{~A}$ ). To assess whether the lower $\mathrm{AT}_{\mathrm{pO}}$ was associated with physiological evidence of hypoxia, we evaluated AT gene expression of hypoxia-inducible factor- $1 \alpha$ (HIF-1 $\alpha$ ), a transcription factor that mediates cellular response to low oxygen tension (18). We found a progressive increase in HIF1A gene expression from the MHL to the MHO to the MUO group with greater gene expression in the MUO group than in the MHL group (Figure 2B) and an inverse association between $\mathrm{AT}_{2}$ and HIF1A gene expression (Supplemental Figure 1; supplemental material available online with this article; https:// doi.org/10.1172/JCI141828DS1). In addition, AT $\mathrm{pO}_{2}$ among all 
Table 1. Body composition and metabolic characteristics of the study subjects

\begin{tabular}{|c|c|c|c|}
\hline & MHL $(n=11)$ & MHO $(n=15)$ & MUO $(n=20)$ \\
\hline Age (years) & $33 \pm 3$ & $37 \pm 2$ & $41 \pm 1^{A}$ \\
\hline BMI $\left(\mathrm{kg} / \mathrm{m}^{2}\right)$ & $22.9 \pm 0.4$ & $36.9 \pm 1.3^{A}$ & $39.1 \pm 1.2^{A}$ \\
\hline Body fat (\%) & $29.2 \pm 1.5$ & $47.2 \pm 1.9^{A}$ & $47.1 \pm 1.3^{A}$ \\
\hline SAAT volume $\left(\mathrm{cm}^{3}\right)$ & $982 \pm 119$ & $3624 \pm 292^{A}$ & $3632 \pm 292^{A}$ \\
\hline IAAT volume $\left(\mathrm{cm}^{3}\right)$ & $431 \pm 69$ & $1014 \pm 129^{A}$ & $1896 \pm 178^{A, B}$ \\
\hline IHTG content (\%) & $1.7 \pm 0.2$ & $2.3 \pm 0.2^{A}$ & $16.7 \pm 1.7^{A, B}$ \\
\hline HbA1c (\%) & $5.0 \pm 0.1$ & $5.1 \pm 0.1$ & $5.7 \pm 0.1^{A}$ \\
\hline Mean adipocyte size $\left(\mu \mathrm{m}^{2}\right)$ & $2006 \pm 128$ & $3236 \pm 297^{A}$ & $3494 \pm 268^{A}$ \\
\hline Triglyceride (mg/dL) & $75 \pm 10$ & $67 \pm 6$ & $159 \pm 18^{A, B}$ \\
\hline HDL-cholesterol (mg/dL) & $62 \pm 4$ & $50 \pm 3^{A}$ & $42 \pm 2^{A, B}$ \\
\hline LDL-cholesterol (mg/dL) & $102 \pm 5$ & $99 \pm 8^{A}$ & $110 \pm 7$ \\
\hline Fasting glucose (mg/dL) & $85 \pm 1$ & $88 \pm 1$ & $100 \pm 2^{A, B}$ \\
\hline Fasting insulin ( $\mu \mathrm{U} / \mathrm{mL})$ & $6 \pm 1$ & $13 \pm 2^{A}$ & $27 \pm 4^{A, B}$ \\
\hline HOMA-IR & $1.2 \pm 0.1$ & $2.9 \pm 0.5^{A}$ & $6.9 \pm 1.1^{A, B}$ \\
\hline Glucose: 2-hour OGTT (mg/dL) & $97 \pm 6$ & $107 \pm 4$ & $174 \pm 6^{A, B}$ \\
\hline HISI (1000/[ $\mu \mathrm{mol} / \mathrm{kg} \mathrm{FFM} / \mathrm{min} \times \mu \mathrm{U} / \mathrm{mL}])$ & $10.6 \pm 1.2$ & $5.4 \pm 0.4^{A}$ & $3.2 \pm 0.3^{\mathrm{A}, \mathrm{B}}$ \\
\hline Glucose Rd/I (nmol/kg FFM/min) / ( $\mu \mathrm{U} / \mathrm{mL})$ & $584 \pm 49$ & $362 \pm 35^{A}$ & $228 \pm 19^{A, B}$ \\
\hline
\end{tabular}

Data are means \pm SEM. FFM, fat-free mass; HbA1c, hemoglobin $\mathrm{A}_{1 \mathrm{c}}$; HDL, high-density lipoprotein; HISI, hepatic insulin sensitivity index; HOMA-IR, homeostasis model assessment of insulin resistance; I, insulin; IAAT, intra-abdominal AT; IHTC, intrahepatic triglyceride; LDL, low-density lipoprotein; MHL, metabolically healthy lean; MHO, metabolically healthy obese; MUO, metabolically unhealthy obese; Rd, rate of disposal; SAAT, subcutaneous abdominal AT. One-way ANOVA and Fisher's least significant difference procedure were used to identify significant differences between groups. ${ }^{A}$ Value significantly different from the corresponding value in the MHL group, $P<0.05$. ${ }^{B}$ Value significantly different from the corresponding value in the $\mathrm{MHO}$ group, $P<0.05$.
RNA sequencing. We found that 1982 genes were significantly $(P<0.005)$ associated with AT $\mathrm{pO}_{2}$. Analysis of the 1207 genes positively associated with $\mathrm{AT} \mathrm{pO}_{2}$ revealed a biological pathway involved in BCAA catabolism to be the most highly enriched (Figure $3 \mathrm{~A})$. The link between $\mathrm{AT}_{\mathrm{pO}}$ and BCAA metabolism was further supported by (a) higher fasting plasma concentrations of the BCAAs leucine, isoleucine, and valine in the MUO group than in the MHL and MHO groups (Figure 4A); (b) negative associations between plasma BCAA concentrations and $\mathrm{AT} \mathrm{pO}_{2}$ (Figure 4B); (c) positive associations between $\mathrm{AT}_{\mathrm{pO}}$ and the expression of genes that encode key enzymes involved in catabolism of BCAAs (Figure 4C); and (d) negative associations between AT HIF1A expression and the expression of genes that encode key enzymes involved in BCAA catabolism (Supplemental Figure 2). The remaining pathways enriched with genes positively associated with $\mathrm{AT} \mathrm{pO}_{2}$ involved the regulation of protein synthesis (Figure 3A). Expression of individual genes encoding translation initiation and elongation factors was also positively associated with AT $\mathrm{pO}_{2}$ (Figure 5).

Genes that were negatively associated with $\mathrm{AT} \mathrm{pO}_{2}$ were highly enriched in mulparticipants was positively correlated with both hepatic and wholebody insulin sensitivity (Figure 2, C and D).

$A T$ oxygen tension is positively correlated with AT BCAA metabolism and protein synthesis and negatively correlated with AT inflammation, fibrosis, and angiogenesis. An unbiased global assessment of AT gene expression in relation to $\mathrm{AT}_{\mathrm{pO}}$ was evaluated using

Figure 2. AT oxygen tension is reduced in MUO and is positively associated with insulin sensitivity. ( $A$ and $\mathbf{B}$ ) AT oxygen partial pressure (AT $\left.\mathrm{pO}_{2}\right)(\mathbf{A})$ and HIF1A gene expression (B) in metabolically healthy lean (MHL; $n=11)$, metabolically healthy obese (MHO; $n=15)$, and metabolically unhealthy obese (MUO; $n=20$ ) groups. Data are means \pm SEM. One-way ANOVA and Fisher's least significant difference procedure were used to identify significant mean differences between groups. *Value significantly different from the MHL value, $P<0.001$. 'Value significantly different from the MHO value, $P<0.05$. "Linear trend, $P<0.001$. (C and $\mathbf{D})$ Relationship between $A T \mathrm{pO}_{2}$ and hepatic insulin sensitivity index (HISI), assessed as 1000 divided by the product of endogenous glucose rate of appearance (in $\mu \mathrm{mol} / \mathrm{kg}$ fat-free mass $/ \mathrm{min}$ ) and plasma insulin concentration (in $\mu \mathrm{U} / \mathrm{mL}$ ) in the overnight fasting state (C), and between $\mathrm{pO}_{2}$ and whole-body insulin sensitivity, assessed as glucose rate of disposal (Rd; in nmol/kg fat-free mass $/ \mathrm{min}$ ) divided by plasma insulin (I) concentration (in $\mu \mathrm{U} / \mathrm{mL}$ ) during a hyperinsulinemic-euglycemic clamp procedure (D), in MHL (white circles; $n=11$ ), MHO (gray circles; $n=15$ ), and MUO (black circles; $n=20$ ) participants. Associations between $\mathrm{AT}_{\mathrm{pO}}$ and $\mathrm{HISI}$ and between $\mathrm{AT} \mathrm{pO}_{2}$ and glucose $\mathrm{Rd} / \mathrm{I}$ were determined using Pearson's correlation coefficient. tiple biological pathways involved in proinflammatory responses (Figure 3B). Moreover, $\mathrm{AT}_{\mathrm{pO}}$ was inversely correlated with the expression of the proinflammatory markers SERPINE1, CD68, CD74, CXCL16, CCL2, CCL5, TNF, and IL6 (Figure 6). In gener$\mathrm{al}$, an increase in AT markers of inflammation did not translate to an increase in plasma concentrations of cytokines and chemo-
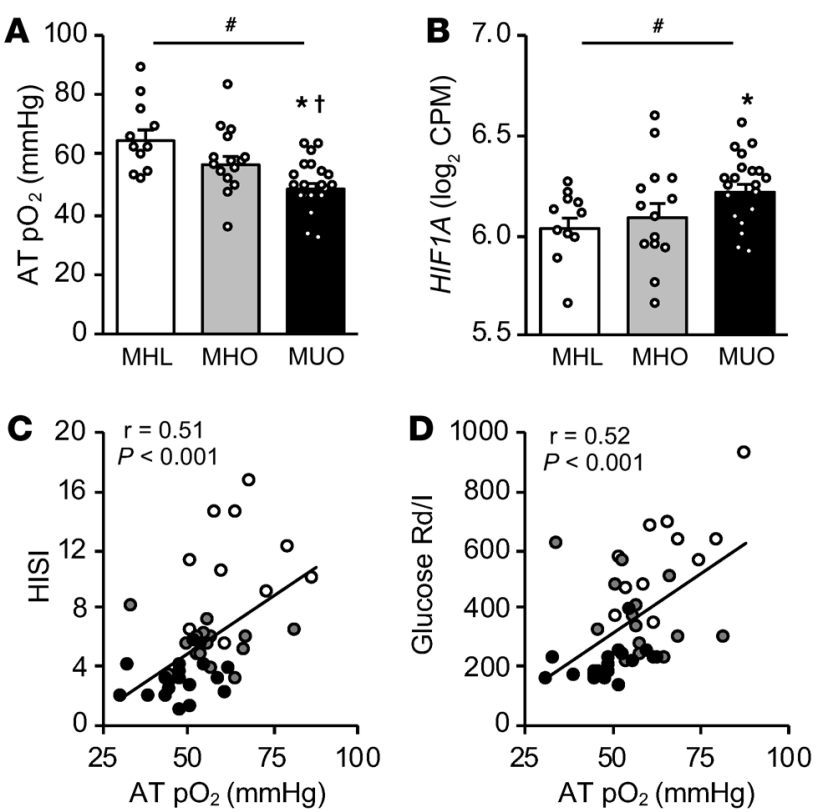


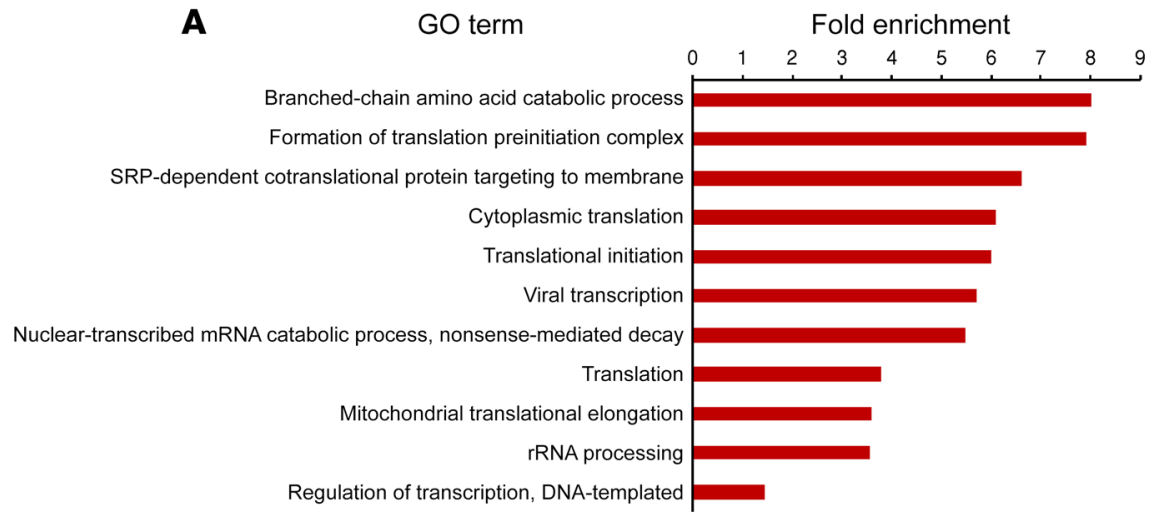

B

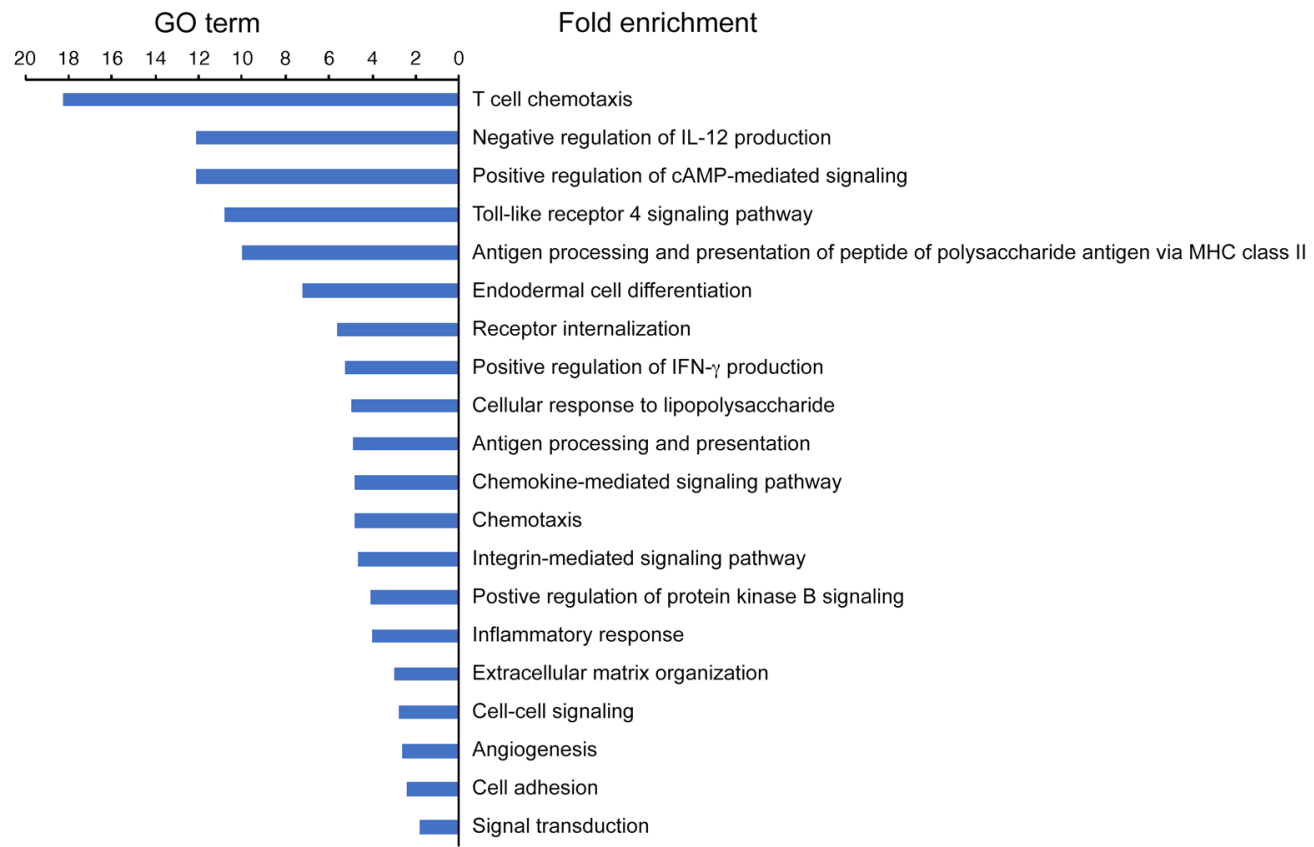

Figure 3. AT biological pathways associated with AT oxygen tension. (A and B) RNA sequencing was conducted in AT samples obtained from MHL ( $n=11$ ), MHO $(n=14)$, and MUO $(n=20)$ participants. Functional enrichment analyses were performed to identify biological pathways significantly (false discovery rate $<0.01$ ) enriched with genes positively (red) (A) and negatively (blue) (B) associated with AT oxygen tension.

kines (Table 2). Plasma concentrations of proinflammatory IFN- $\gamma$, TNF- $\alpha$, IL-6, CCL-2, and CCL-5 were not greater in the MUO group than in the MHO and MHL groups, and plasma concentration of the antiinflammatory cytokine IL-10 was not different among the 3 groups. However, plasma concentration of PAI-1, which is the protein product of AT SERPINE1, was greater in the MUO than in the MHO and MHL groups and was inversely correlated with $\mathrm{AT} \mathrm{pO}_{2}$ (Table 2).

Genes negatively associated with $\mathrm{AT}_{\mathrm{pO}}$ were also enriched in pathways related to extracellular matrix (ECM) remodeling (Figure 3B), with expression of genes regulating the formation, cross-linking, and stabilization of the ECM inversely correlated with $\mathrm{AT}_{\mathrm{pO}}$ (Figure 7). In addition, genes negatively associated with $\mathrm{AT} \mathrm{pO}_{2}$ were enriched in a pathway involved in regulating angiogenesis (Figure $3 \mathrm{~B}$ ), which was driven by genes regulating inflammation and ECM remodeling in this gene set (Supplemental Table 1). In contrast, VEGFA gene expression, which is a major regulator of angiogenesis $(19,20)$, progressively decreased from the MHL to the MHO to the MUO group and was positively associated with $\mathrm{AT}_{2} \mathrm{pO}_{2}$ (Figure 8). Our VEGFA results are consistent with data from previous studies that found higher AT HIF1A gene expression but lower VEGFA expression in a rodent model of obesity (21) and lower AT VEGFA expression in people with obesity than in people who are lean $(12,16)$.

\section{Discussion}

Studies conducted in rodent models have shown that AT hypoxia is involved in the pathogenesis of obesity-induced insulin resistance due to alterations in AT biological processes. In the present study, we evaluated whether decreased $\mathrm{AT} \mathrm{pO}_{2}$ in people with obesity is also associated with alterations in AT biology and a concomitant impairment in insulin action. To this end, we evaluated subcutaneous abdominal AT $\mathrm{pO}_{2}$, hepatic and whole-body insulin sensitivity, AT markers of inflammation, fibrosis, and BCAA 
A
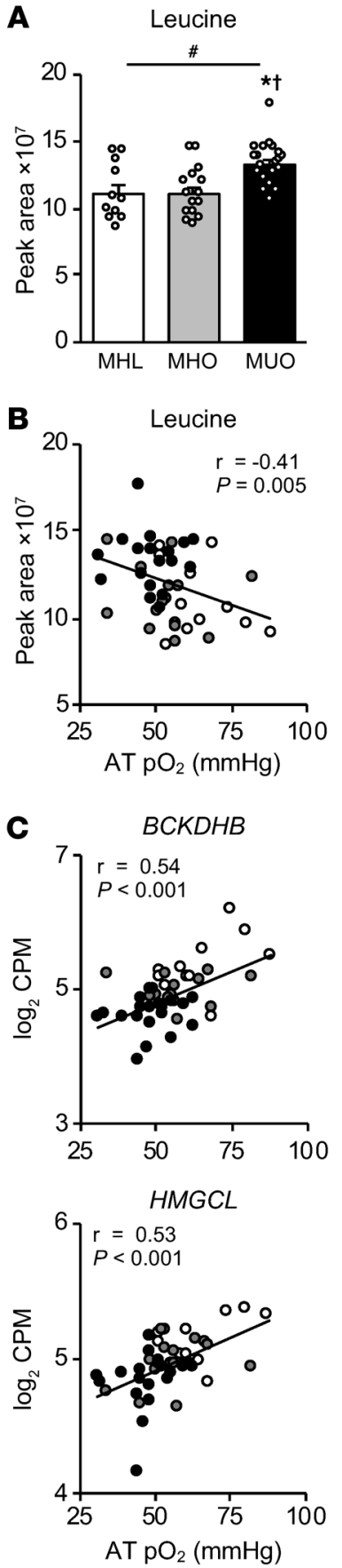
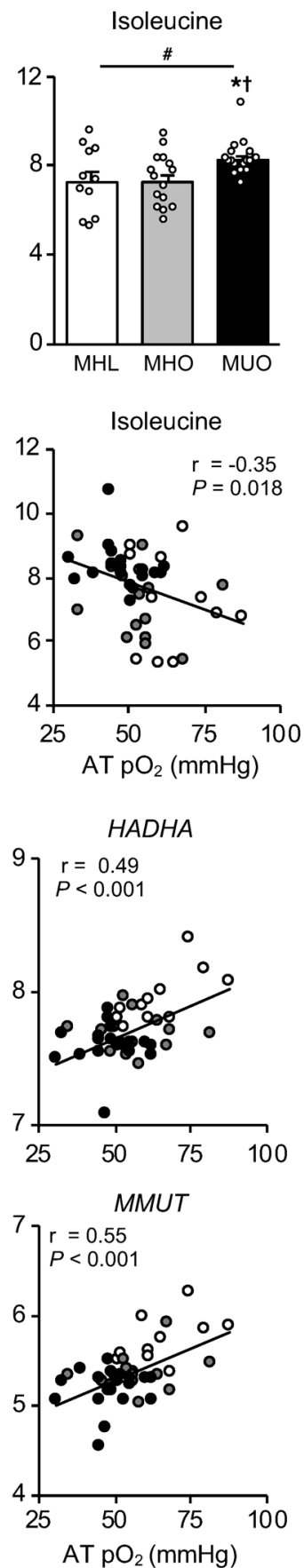
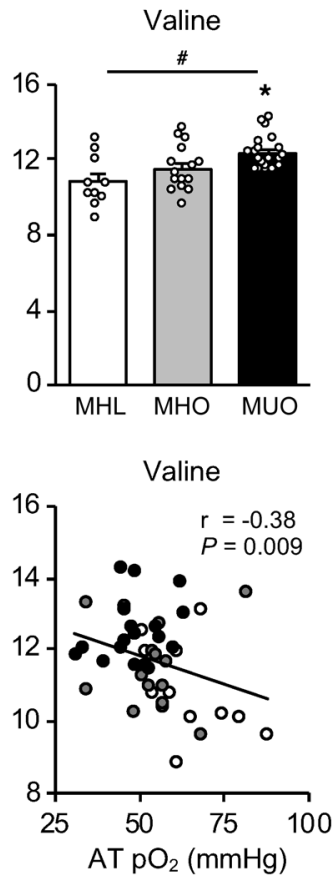

Figure 4. AT oxygen tension is negatively associated with plasma BCAA concentrations and positively associated with AT expression of genes involved in BCAA catabolism. (A) Fasting plasma leucine, isoleucine, and valine concentrations in $\mathrm{MHL}(n=11), \mathrm{MHO}(n=15)$, and MUO $(n=20)$ groups. Data are means \pm SEM. One-way ANOVA and Fisher's least significant difference procedure were used to identify significant differences between groups. *Value significantly different from the corresponding MHL value, $P<0.05$. ${ }^{\dagger}$ Value significantly different from the corresponding $\mathrm{MHO}$ value, $P<0.05$. "Significant linear trend for the 3 groups, $P<0.05$. (B and $\mathbf{C}$ ) Relationship between $\mathrm{AT} \mathrm{pO}_{2}$ and plasma leucine, isoleucine, and valine concentrations (B) and AT gene expression of key enzymes involved in BCAA catabolism (C) in MHL (white circles; $n=11$ ), MHO (gray circles $n=15$ in B and $n=14$ in C), and MUO (black circles; $n=20$ ) participants. Associations between $\mathrm{AT} \mathrm{pO}_{2}$ and plasma BCAA concentrations and between AT $\mathrm{pO}_{2}$ and AT gene expression were determined using Pearson's correlation coefficient.
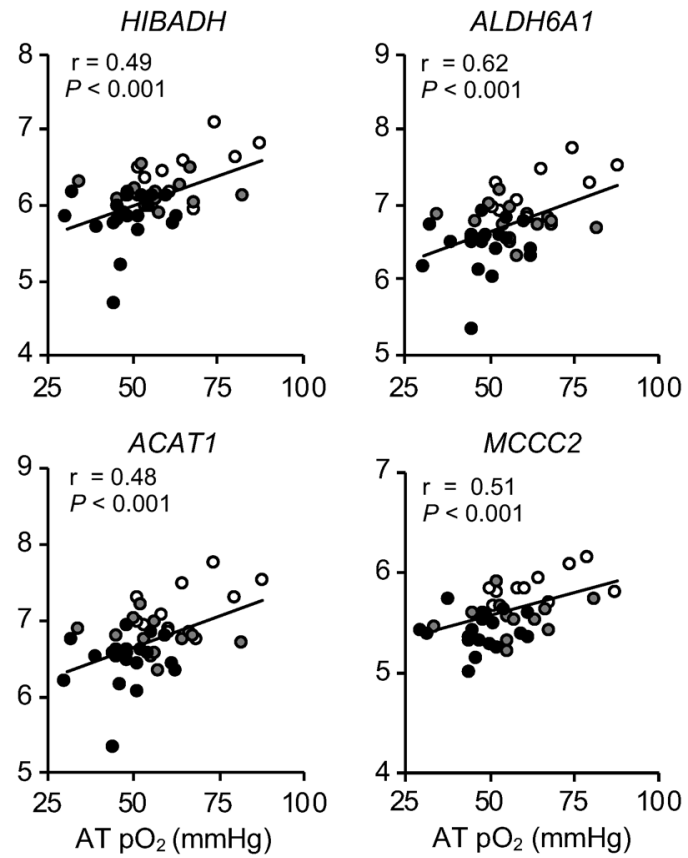

catabolism, and related circulating factors proposed to be involved in the pathogenesis of insulin resistance in 3 distinct groups of participants that were stratified by insulin sensitivity and adiposity. We found that $\mathrm{AT}_{\mathrm{pO}}$ progressively declined and AT expression of HIF1A progressively increased from the MHL to the MHO to the MUO group and positively correlated with hepatic and whole-body insulin sensitivity. In addition, $\mathrm{AT}_{\mathrm{pO}_{2}}$ was negatively associated with AT gene expression of markers of inflammation and ECM remodeling. Plasma PAI-1 concentration increased progressively from the MHL to the MHO to the MUO group and was negatively associated with $\mathrm{AT}_{\mathrm{pO}_{2}}$. In contrast, most plasma concentrations of cytokines and chemokines were not different among the MHL, $\mathrm{MHO}$, and MUO groups and did not correlate with AT $\mathrm{pO}_{2}$. We also found positive associations between $\mathrm{AT}_{\mathrm{pO}}$ and the expression of genes involved in BCAA catabolism, in conjunction with an inverse relationship between $\mathrm{AT}_{\mathrm{pO}}$ and plasma BCAA concentrations. Together, these data demonstrate a link between AT oxygenation and AT inflammation, fibrogenesis, and BCAA catabolism, and suggest that decreased $\mathrm{AT}_{\mathrm{pO}}$ in people contributes to insulin resistance by increasing AT PAI-1 production (encoded by SERPINE1) and decreasing AT BCAA catabolism, thereby increasing plasma PAI-1 and BCAA concentrations.

The adequacy of adipocyte oxygenation is determined by the rate of arterial $\mathrm{O}_{2}$ delivery to AT, the ability of $\mathrm{O}_{2}$ to diffuse from AT capillaries to adipocytes, and the rate of adipocyte $\mathrm{O}_{2}$ consumption. People with obesity are therefore at increased risk 

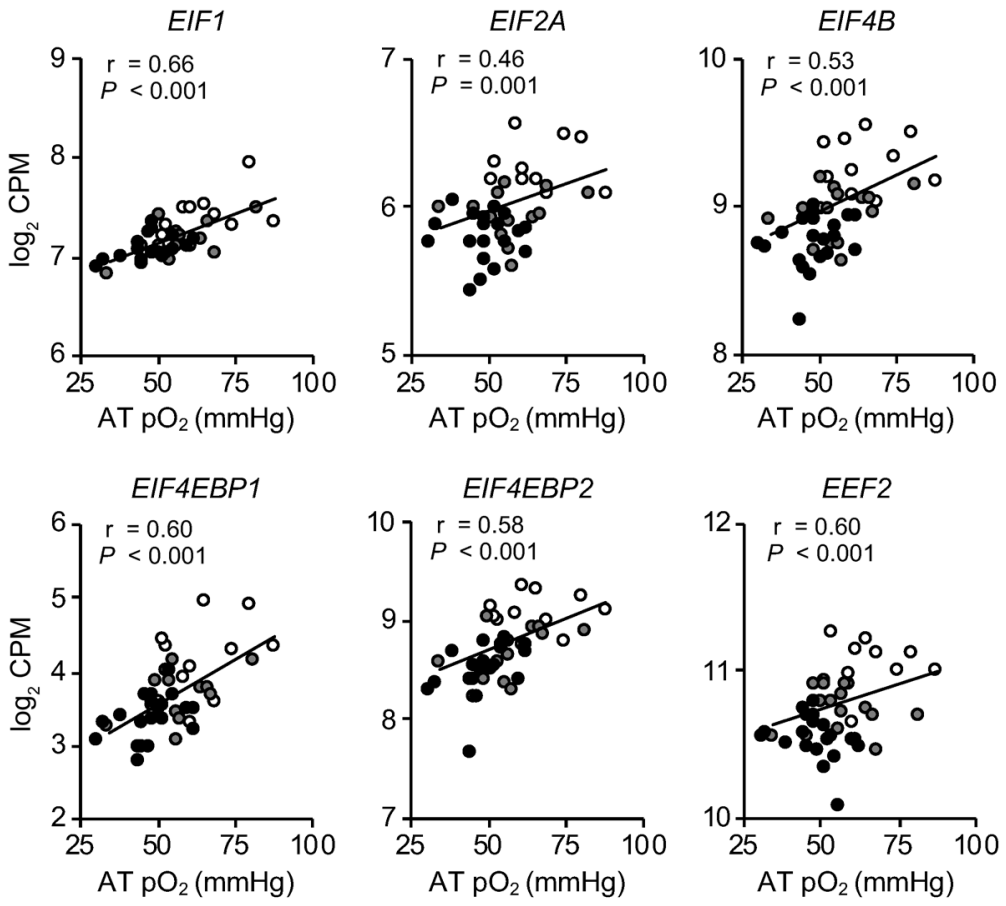

Figure 5. AT oxygen tension is positively associated with AT expression of genes involved in regulating protein synthesis. Relationship between $\mathrm{AT} \mathrm{pO}_{2}$ and expression of AT genes involved in regulating protein synthesis in MHL (white circles; $n$ $=11$ ), MHO (gray circles; $n=14$ ), and MUO (black circles; $n=20$ ) participants. Associations between $\mathrm{AT}$ pO $\mathrm{O}_{2}$ and AT gene expression were determined using Pearson's correlation coefficient.

$\mathrm{O}_{2}$ consumption is likely related to decreased AT energy requirements, because people with obesity have fewer, but larger lipid-laden adipocytes per gram of AT (28). We found that $\mathrm{AT}_{\mathrm{pO}_{2}}$ was highest in the MHL group and that $\mathrm{AT}_{\mathrm{pO}}$ was lower in people with $\mathrm{MUO}$ than $\mathrm{MHO}$ even though there was no difference in AT mass or adipocyte size between the groups with obesity. These findings suggest that decreased AT $\mathrm{O}_{2}$ delivery, increased $\mathrm{O}_{2}$ consumption, or both contribute to decreased $\mathrm{AT}_{\mathrm{pO}}$ in people with MUO compared with people with $\mathrm{MHO}$.

We found a positive correlation between $\mathrm{AT} \mathrm{pO}_{2}$ and whole-body insulin sensitivity with respect to glucose metabolism, which is inconsistent with results from previous studies that found that $\mathrm{AT}_{\mathrm{pO}}$ was negof adipocyte hypoxia because (a) systemic arterial $\mathrm{O}_{2}$ content is usually decreased in people with obesity due to pulmonary dysfunction $(22,23)$; (b) AT blood flow is much lower in people with obesity than in people who are lean $(16,24-26)$; (c) AT capillary density decreases with excess adiposity $(12,13,16)$; and (d) adipocyte hypertrophy increases the $\mathrm{O}_{2}$ diffusion distance from capillaries to adipocytes (27). However, data from studies conducted in vivo suggest that $\mathrm{O}_{2}$ consumption per gram of AT is lower in people with obesity than in those who are lean $(16,22)$. This decrease in atively associated $(16,17)$ or not associated $(12,14)$ with insulin sensitivity. The discrepancy in findings among studies could be related to differences in the techniques used to measure AT $\mathrm{pO}_{2}$ (i.e., optochemical [refs. 16, 17] versus $\mathrm{O}_{2}$ electrode [refs. 12-15] methods), differences in the criteria used to define insulin-resistant and insulin-sensitive cohorts, and inadequate numbers of subjects to detect statistically significant effects. Nonetheless, our results are consistent with previous studies that found that (a) AT oxygenation was decreased in genetic and diet-induced rodent
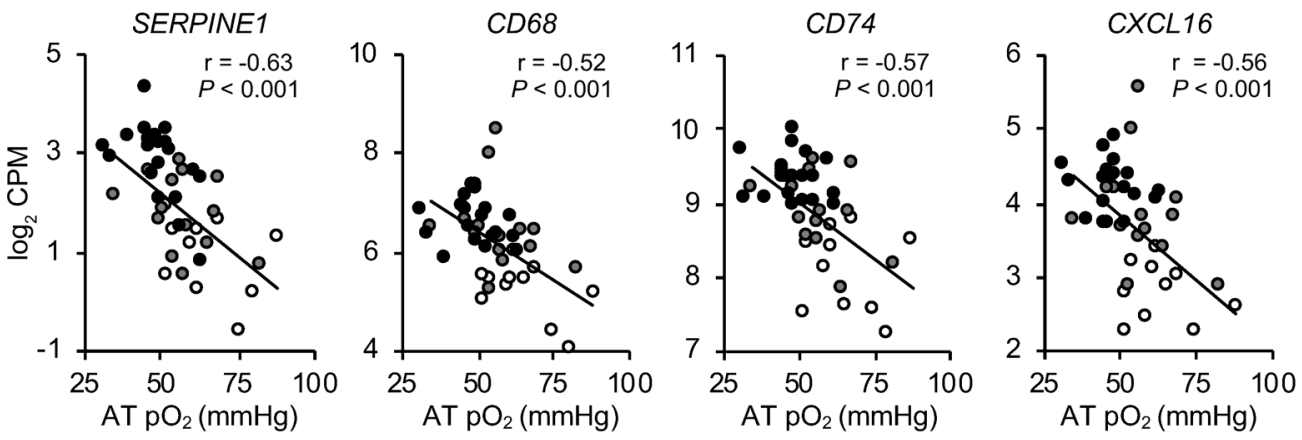

Figure 6. AT oxygen tension is inversely associated with AT expression of genes related to inflammation. Relationship between $\mathrm{AT} \mathrm{pO}_{2}$ and AT expression of genes related to inflammation in MHL (white circles; $n=11$ ), MHO (gray circles; $n=$ 14), and MUO (black circles; $n=20$ ) participants. Associations between AT $\mathrm{pO}_{2}$ and $\mathrm{AT}$ gene expression were determined using Pearson's correlation coefficient.
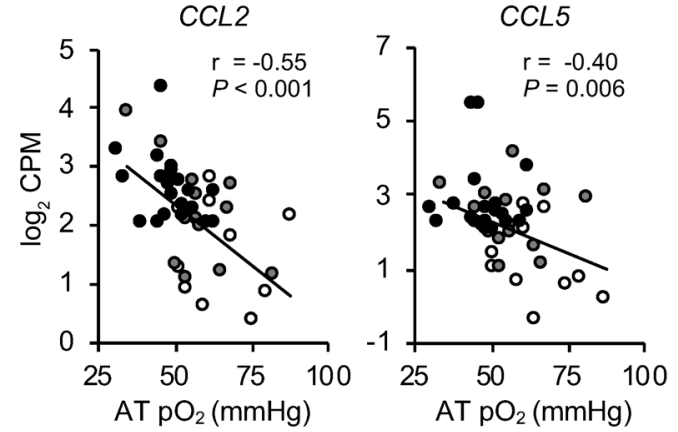

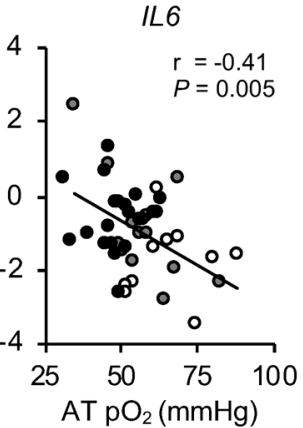


Table 2. Plasma markers of inflammation

\begin{tabular}{|c|c|c|c|c|c|}
\hline & \multirow{2}{*}{$\begin{array}{c}\text { MHL } \\
(n=11)\end{array}$} & \multirow{2}{*}{$\begin{array}{c}\text { MHO } \\
(n=15)\end{array}$} & \multirow{2}{*}{$\begin{array}{c}\text { MUO } \\
(n=20)\end{array}$} & \multicolumn{2}{|c|}{ Correlation with $\mathrm{AT} \mathrm{pO}_{2}$} \\
\hline & & & & $r$ & $P$ value \\
\hline TNF- $\alpha$ (pg/mL) & $1.6 \pm 0.2$ & $1.9 \pm 0.2$ & $1.5 \pm 0.1$ & -0.15 & 0.31 \\
\hline IL-6 (pg/mL) & $2.3 \pm 0.5$ & $2.6 \pm 0.3$ & $2.4 \pm 0.5$ & -0.12 & 0.44 \\
\hline IFN- $\gamma(\mathrm{pg} / \mathrm{mL})$ & $4.3 \pm 0.5^{B}$ & $6.9 \pm 0.9$ & $4.4 \pm 0.5^{B}$ & -0.20 & 0.20 \\
\hline IL-10 (pg/mL) & $3.5 \pm 1.0$ & $6.85 \pm 2.1$ & $10.3 \pm 5.0$ & -0.19 & 0.20 \\
\hline CCL-2 (pg/mL) & $63.4 \pm 9.2$ & $75.5 \pm 20.1$ & $57.8 \pm 10.5$ & -0.01 & 0.92 \\
\hline CCL-5 (ng/mL) & $1.2 \pm 0.3$ & $1.3 \pm 0.6$ & $2.9 \pm 0.8$ & -0.33 & 0.03 \\
\hline PAI-1 (ng/mL) & $4.2 \pm 1.5$ & $15.2 \pm 9.3$ & $47.2 \pm 14.4^{A, B}$ & -0.37 & 0.01 \\
\hline
\end{tabular}

Plasma concentrations of cytokines and chemokines and their association with $\mathrm{AT}_{\mathrm{pO}}$, in $\mathrm{MHL}, \mathrm{MHO}$, and MUO groups. Data are means \pm SEM. One-way ANOVA and Fisher's least significant difference procedure were used to identify significant differences between groups. Associations between plasma cytokine/chemokine concentrations and $\mathrm{AT}_{\mathrm{pO}}$ were determined using Pearson's correlation coefficient. Non-normally distributed variables were log-transformed for statistical analysis. ${ }^{A}$ Value significantly different from the MHL value,

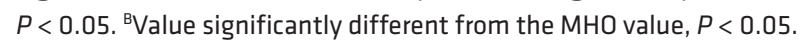

sion of proinflammatory markers [refs. 5, 21, 29], macrophage infiltration [ref. 29], and polarization toward proinflammatory M1-like macrophages [refs. 37, 38]) and fibrosis $(21,39)$. We found an inverse relationship between AT oxygenation and the expression of genes involved in inflammation, consistent with data from studies conducted in cultured adipocytes that found that hypoxia increased the expression of genes involved in inflammation, including TNFA, IL6, and SERPINE1 $(40,41)$. However, with the exception of plasma PAI-1, we did not detect a corresponding increase in circulating proinflammatory cytokines and chemokines. Plasma PAI-1 concentrations progressively increased from the MHL to the MHO to the MUO group and were negatively associated with $\mathrm{AT}_{\mathrm{pO}_{2}}$. Increased plasma PAI-1 is associated with insulin resistance (42) and is an independent risk factor for developing T2D $(43,44)$. Moreover, whole-body and adipocyte-specific knockouts of PAI-1 improve insulin action $(45,46)$, whereas adipocyte-specific PAI-1

models of obesity and insulin resistance (29-31); (b) prolonged (16-24 hours) hypoxia causes insulin resistance in cultured adipocytes $(30,32)$; (c) experimentally induced reductions in $\mathrm{AT}_{2}$ consumption improved glucose tolerance and insulin sensitivity in rodent models of obesity $(5,33)$; (d) hyperbaric oxygen therapy increases insulin sensitivity $(34,35)$; and (e) acute hypoxia causes insulin resistance in people (36).

Our study cannot determine whether the relationship we observed between $\mathrm{AT}_{\mathrm{pO}}$ and insulin sensitivity is causal or simply an association. Reduced AT oxygenation in rodent models of obesity has been proposed to cause systemic insulin resistance, at least in part, by inducing AT inflammation (increased gene expresoverexpression causes insulin resistance (47). It is also possible that other mediators associated with AT inflammation and macrophage infiltration, such as AT macrophage-derived exosomes that cause systemic insulin resistance in rodent models (48), also cause insulin resistance in people.

Increased plasma BCAA concentrations are associated with insulin resistance, prediabetes, and type 2 diabetes in people (49-52), and weight loss-induced improvements in insulin sensitivity are associated with a decrease in plasma BCAA concentrations $(53,54)$. It is likely that multiple mechanisms are responsible for BCAA-induced insulin resistance (55), including mammalian target of rapamycin-mediated (mTOR-mediated) inhibition of
Figure 7. AT oxygen tension is inversely associated with AT expression of genes involved in ECM remodeling. Relationship between $\mathrm{AT} \mathrm{pO}_{2}$ and $\mathrm{AT}$ expression of genes involved in ECM remodeling in MHL (white circles; $n=$ 11), MHO (gray circles; $n=14$ ), and MUO (black circles; $n=20$ ) participants. Associations between AT $\mathrm{pO}_{2}$ and AT gene expression were determined using Pearson's correlation coefficient.
COL3A1

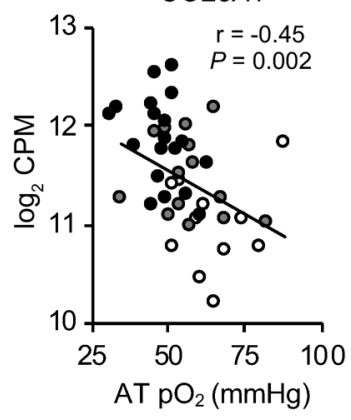

LOXL1

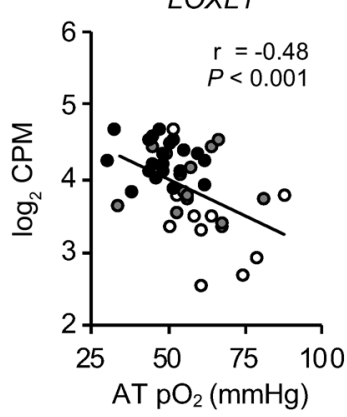

COL6A2

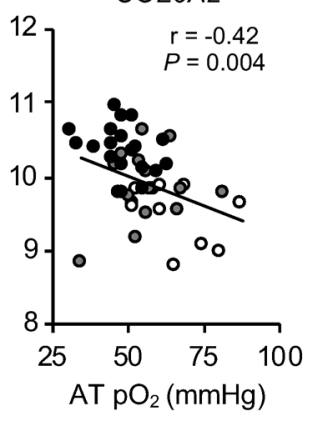

LOXL2

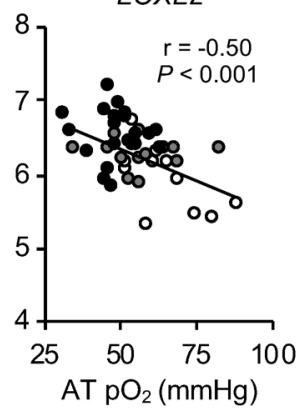

CTGF

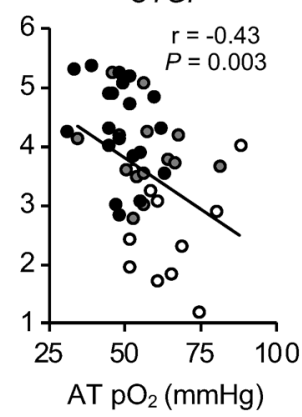

LOXL3

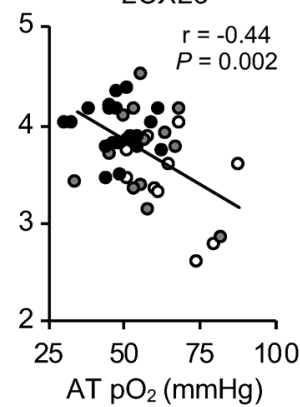

MFAP5

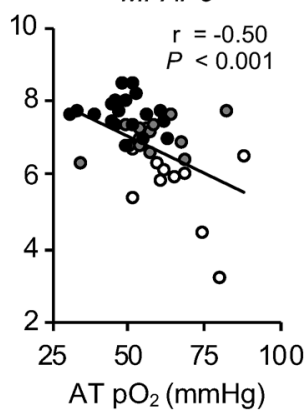

MMP9

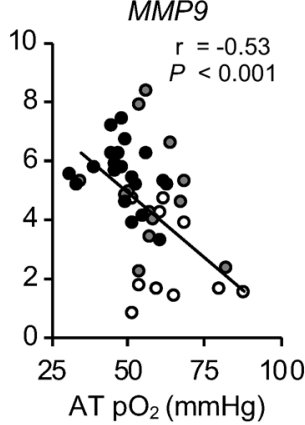


Figure 8. AT oxygen tension is positively associated with AT VECFA expression. (A) AT VEGFA gene expression in MHL $(n=11)$, MHO $(n=14)$, and MUO $(n=20)$ groups. Data are means \pm SEM. One-way ANOVA and Fisher's least significant difference procedure were used to identify significant mean differences between groups. ${ }^{*}$ Value significantly different value, $P<0.05$. "Linear trend, $P<0.001$. (B) Relationship between $\mathrm{AT}_{\mathrm{pO}}$ and AT VEGFA gene expression in MHL (white circles; $n=11$ ), MHO (gray circles; $n=14$ ), and MUO (black circles; $n=20$ ) participants. Associations between AT $\mathrm{pO}_{2}$ and AT gene expression were determined using Pearson's correlation coefficient. from the MHL value, $P<0.001$. 'Value significantly different from the MHO
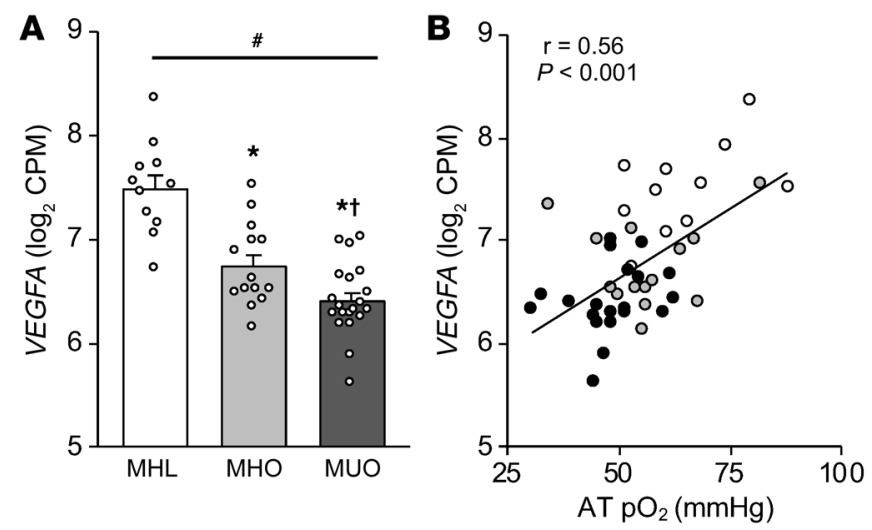

in HIF-1 $\alpha$, a transcription factor that acts as a molecular oxygen sensor (64). Although considerable posttranslational modification of HIF-1 $\alpha$ influences its activity (65), an increase in HIF1A gene expression is also a robust marker of AT hypoxia $(31,33,66)$. We found a progressive increase in AT HIF1A gene expression from the MHL to the $\mathrm{MHO}$ to the MUO group. Moreover, $\mathrm{AT}_{\mathrm{TO}}$ was inversely associated with AT gene expression of several HIF-1 $\alpha$ targets that cause AT inflammation and fibrosis induced by hypoxia $(33,67,68)$, including PAI-1 (69), lysyl oxidase (21), and connective tissue growth factor (70). Accordingly, our data suggest that the reduction in $\mathrm{AT}_{\mathrm{pO}}$ observed in the $\mathrm{MHO}$ and $\mathrm{MUO}$ groups was sufficient to stimulate a physiological response to hypoxia.

In summary, we found a progressive decrease in AT oxygen tension and a progressive increase in HIF1A gene expression from people who are MHL to MHO to MUO. AT $\mathrm{pO}_{2}$ was negatively correlated with AT expression of genes involved in inflammation and ECM formation and positively correlated with AT expression of genes involved BCAA catabolism. In addition, $\mathrm{AT}_{\mathrm{pO}}$ was negatively correlated with both plasma PAI- 1 and BCAA concentrations, and positively correlated with both hepatic and whole-body insulin sensitivity. Together, these data suggest that decreased AT $\mathrm{pO}_{2}$ contributes to insulin resistance in people with obesity by causing a constellation of alterations in AT biology that lead to an increase in plasma PAI-1 and BCAA concentrations (Figure 9). Therefore, differences in the decrease in $\mathrm{AT}_{\mathrm{pO}}$ associated with AT expansion provide a potential mechanism that contributes to the differences in insulin sensitivity between people with metabolically healthy and metabolically unhealthy obesity.

\section{Methods}

in $\mathrm{AT} \mathrm{pO}_{2}$ among our cohorts were adequate to induce a physiological response to hypoxia. We used oxygen-sensitive fiber optic probes, which measure $\mathrm{O}_{2}$ partial pressures in AT interstitial space but do not measure intracellular adipocyte $\mathrm{pO}_{2}$. This technical limitation is common to all studies conducted in people, which report AT extracellular rather than intracellular $\mathrm{pO}_{2}(12-17)$. Studies conducted in cell systems in vitro have shown that intracellular $\mathrm{pO}_{2}$ is lower than extracellular $\mathrm{pO}_{2}$, but the relative difference is maintained across a wide range of oxygen tensions (63). Therefore, our measurement of interstitial $\mathrm{AT}_{\mathrm{pO}}$ likely provides a reliable index of intra-adipocyte $\mathrm{pO}_{2}$. In addition, we assessed AT HIF1A gene expression as an index of physiological AT hypoxia. The cellular response to hypoxia in adipocytes is mediated through an increase

\section{Subjects}

Forty-six men and women (age $37.9 \pm 1.2$ years old) participated in this study, which was conducted in the Clinical Translational Research Unit (CTRU) at Washington University School of Medicine in St. Louis (Missouri, USA) from May 2016 to April 2019. Participants were recruited using the Volunteers for Health database at Washington University School of Medicine and by local postings. Written, informed consent was obtained from all participants before their participation in this study, which was approved by the Human Research Protection Office of Washington University and registered in ClinicalTrials.gov (NCT02706262). All participants completed a screening evaluation 


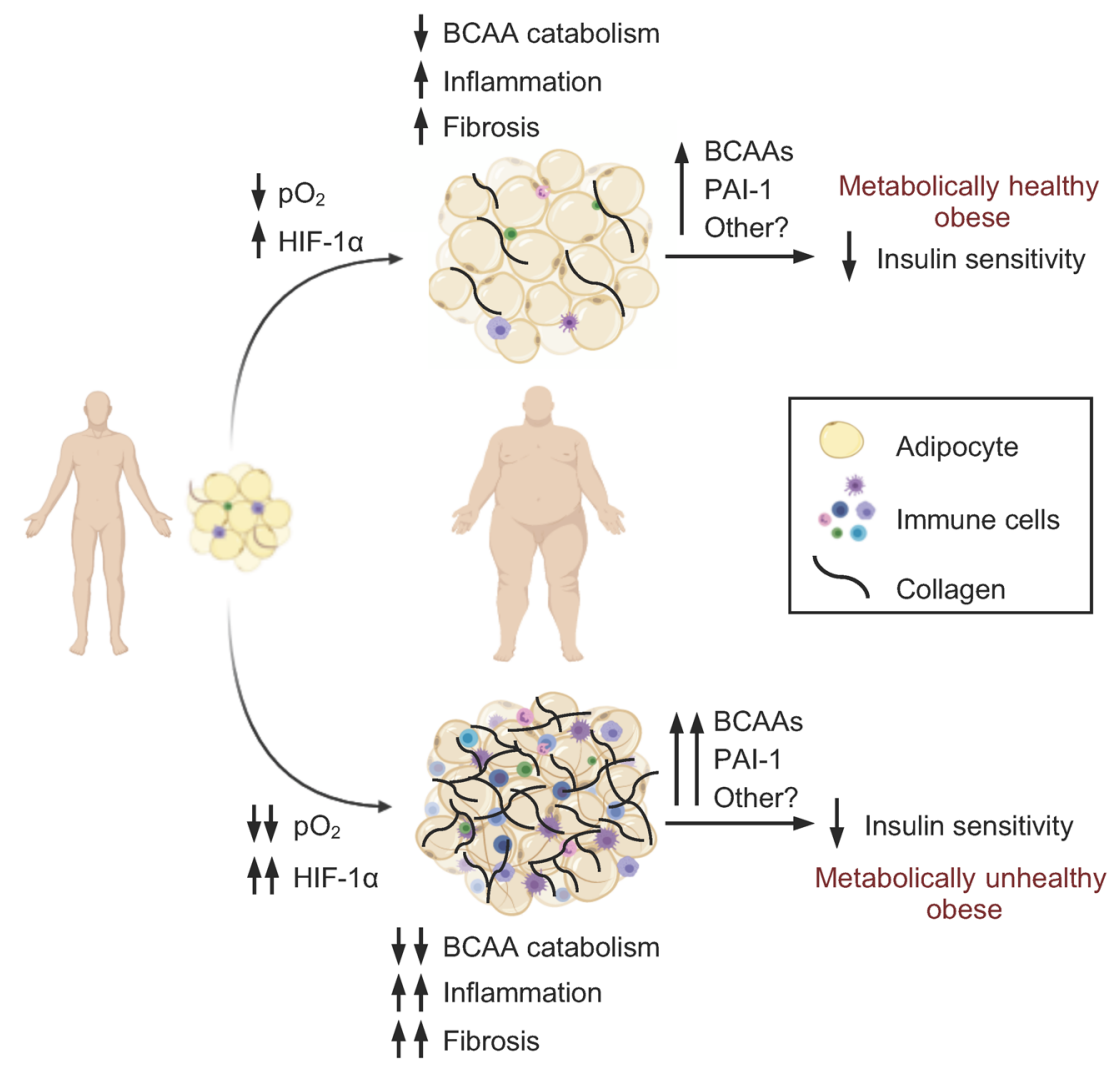

Figure 9. Proposed effects of decreased AT oxygen tension on AT biology and insulin sensitivity in people with obesity. An increase in AT mass associated with obesity decreases $\mathrm{AT} \mathrm{pO}_{2}$, which increases AT HIF-1 $\alpha$ expression and triggers a cascade of alterations in AT biology, including a decrease in BCAA catabolism and an increase in inflammation and fibrosis. These changes lead to an increase in circulating BCAAs and PAI-1 that impair systemic insulin action. Differences in $\mathrm{AT} \mathrm{pO}_{2}$ among people with obesity provide a potential mechanism to help explain the differences in insulin sensitivity between people with metabolically healthy and metabolically unhealthy obesity.

that included a medical history and physical examination, standard blood tests, hemoglobin $\mathrm{A}_{1 \mathrm{c}}$ (HbA1c), an oral glucose tolerance test (OGTT), and assessment of IHTG content by MRI. The following inclusion criteria were required for each of the 3 groups: (a) MHL ( $n=11,6$ women) had BMI $18.5-24.9 \mathrm{~kg} / \mathrm{m}^{2}$, plasma TG concentration $<150 \mathrm{mg} / \mathrm{dL}$, fasting plasma glucose concentration $<100 \mathrm{mg} /$ $\mathrm{dL}$, 2-hour OGTT plasma glucose concentration $<140 \mathrm{mg} / \mathrm{dL}, \mathrm{HbA} 1 \mathrm{c}$ $\leq 5.6 \%$, and IHTG content $<4 \%$; (b) MHO ( $n=15,13$ women) had BMI $30-49.9 \mathrm{~kg} / \mathrm{m}^{2}$, plasma TG concentration $<150 \mathrm{mg} / \mathrm{dL}$, fasting plasma glucose concentration $<100 \mathrm{mg} / \mathrm{dL}, 2$-hour OGTT plasma glucose concentration $<140 \mathrm{mg} / \mathrm{dL}, \mathrm{HbA} 1 \mathrm{c} \leq 5.6 \%$, and IHTG content $<4 \%$; and (c) MUO ( $n=20,15$ women) had BMI $30-49.9 \mathrm{~kg} / \mathrm{m}^{2}$, prediabetes (fasting plasma glucose concentration $\geq 100 \mathrm{mg} / \mathrm{dL}$, 2-hour OGTT plasma glucose concentration $\geq 140 \mathrm{mg} / \mathrm{dL}$, and/or HbA1c $\geq 5.7 \%$ ), and IHTG content $\geq 5 \%$. Potential participants who had a history of diabetes or liver disease other than nonalcoholic fatty liver disease, were taking medications that could affect the study outcome measures, or consumed excessive amounts of alcohol ( $>21$ drinks per week for men and $>14$ drinks per week for women) were excluded. Three participants (1 person with MHO and 2 people with MUO) had a history of obstructive sleep apnea.

\section{Experimental procedures}

Body composition analyses. Body fat mass and fat-free mass (FFM) were determined by dual-energy x-ray absorptiometry (DXA; Lunar iDXA, GE Healthcare Lunar). Subcutaneous abdominal and intra-abdominal AT volumes and IHTG content were determined by MRI (3-T superconducting magnet, Siemens).

Hyperinsulinemic-euglycemic clamp procedure. Subjects were admitted to the inpatient unit of the Washington University CTRU at 1800 hours for about 48 hours. Subjects were given standard meals, each containing one-third of their estimated daily energy requirements (71), at 1900 hours on the day of admission (day 0) and at 0700 hours, 1300 hours, and 1900 hours on day 1 . A hyperinsulinemic-euglycemic clamp procedure was performed on day 2, after subjects fasted for 11 hours overnight. At 0600 hours, catheters were inserted into an arm vein for the infusion of stable isotopically labeled glucose, insulin, and dextrose and into a radial artery for blood sampling. At 0700 hours, a primed $(8.0 \mu \mathrm{mol} / \mathrm{kg})$ continuous $(0.08 \mu \mathrm{mol} / \mathrm{kg} / \mathrm{min})$ infusion of $\left[\mathrm{U}-{ }^{13} \mathrm{C}\right.$ ]glucose (Cambridge Isotope Laboratories Inc.) was started and maintained for 210 minutes. At 1030 hours, insulin was infused for 210 minutes at a rate of $50 \mathrm{mU} / \mathrm{m}^{2}$ body surface area (BSA)/min (initiated with a 2-step priming dose of $200 \mathrm{mU} / \mathrm{m}^{2} \mathrm{BSA} / \mathrm{min}$ for 5 minutes followed by $100 \mathrm{mU} / \mathrm{m}^{2} \mathrm{BSA} / \mathrm{min}$ for 5 minutes). The infusion of $\left[\mathrm{U}-{ }^{13} \mathrm{C}\right]$ glucose was stopped during insulin infusion because of the expected decrease in hepatic glucose production (72). Euglycemia $(100 \mathrm{mg} / \mathrm{dL})$ was maintained by infusion of $20 \%$ dextrose, enriched to approximately $1 \%$ with $\left[\mathrm{U}-{ }^{13} \mathrm{C}\right]$ glucose. Blood samples were obtained before the beginning of the tracer infusion to assess background plasma glucose tracer enrichment and plasma cytokine, chemokine, and BCAA concentrations, and every 6-7 minutes during the last 20 minutes of the basal and insulin infusion periods to assess glucose kinetics and plasma insulin concentrations; additional blood samples were obtained every 10 minutes throughout the clamp procedure to monitor blood glucose concentrations.

AT $\mathrm{pO}_{2}$ measurement and biopsies. $\mathrm{AT}_{\mathrm{pO}_{2}}$ was measured during the basal period of the clamp procedure. The periumbilical area was cleaned with alcohol and anesthetized with $1 \%$ lidocaine. A small $(\sim 0.5 \mathrm{~cm})$ skin incision was made with a scalpel and a sterile, $250-\mu \mathrm{m}$-diameter, oxygen-sensitive fiber optic probe (OxyLite, Oxford Optronix Ltd.), which 
was inserted through the incision $3 \mathrm{~cm}$ into subcutaneous abdominal AT (SAAT). This probe measures interstitial $\mathrm{pO}_{2}$ at the tip of the probe and provides an accurate assessment of $\mathrm{pO}_{2}$ across the physiological range in $\operatorname{AT}(73,74)$. The fiber optic probe was held in place for 2 minutes, and measurements of $\mathrm{pO}_{2}$ were obtained every 10 seconds; $\mathrm{AT} \mathrm{pO}_{2}$ was calculated as the average $\mathrm{pO}_{2}$ recorded during steady-state conditions, defined as less than a $10 \%$ variance in $\mathrm{pO}_{2}$ for at least 40 seconds. An AT biopsy was then obtained with a conchotome forceps and placed in $10 \%$ formalin before being embedded in paraffin; additional SAAT was obtained by manual aspiration using a $4-\mathrm{mm}$ liposuction cannula (Tulip Medical Products) connected to a 60-cc syringe. Aspirated tissue was immediately rinsed in ice-cold saline and frozen in liquid nitrogen before being stored at $-80^{\circ} \mathrm{C}$ until further processing.

\section{Sample analysis and calculations}

Plasma substrate, insulin, and cytokine concentrations. Plasma glucose concentration was determined using the glucose oxidase method (YSI Inc.). Plasma insulin, HbA1c, and lipid profile were measured in the Washington University Core Laboratory for Clinical Studies, as previously described (75). The homeostasis model assessment of insulin resistance (HOMA-IR) was calculated as the product of fasting plasma insulin (in $\mu \mathrm{U} / \mathrm{mL}$ ) and glucose (in $\mathrm{mmol} / \mathrm{L}$ ) concentrations divided by 22.5 (76). Plasma BCAA concentrations were determined using liquid chromatography-tandem mass spectrometry as previously described (77). Plasma cytokine and chemokine concentrations were determined using commercially available magnetic bead suspension assays (MilliporeSigma and R\&D Systems) and a Luminex 200 analyzer (Luminex Corp.).

Glucose kinetics. Plasma glucose tracer-to-tracee ratio (TTR) was determined by gas chromatography-mass spectrometry as previously described (78). Hepatic insulin sensitivity was calculated as the reciprocal of the product of basal plasma insulin concentration (in $\mu \mathrm{U} / \mathrm{mL}$ ) and basal endogenous glucose production rate (in $\mu \mathrm{mol} / \mathrm{kg}$ FFM/ $\mathrm{min}$ ) determined by division of the glucose tracer infusion rate by the average plasma glucose TTR during the last 20 minutes of the basal period of the clamp procedure (79). The total glucose rate of disposal (Rd) during insulin infusion was assumed to be equal to the sum of the endogenous glucose rate of appearance into the bloodstream and the rate of infused glucose during the last 20 minutes of the clamp procedure. Whole-body insulin sensitivity was calculated as glucose Rd per kilogram FFM divided by the average plasma insulin concentration (glucose Rd/I) during the final 20 minutes of the clamp procedure (79).

Adipocyte size. Adipocyte areas were assessed by evaluation of histological sections of AT stained with H\&E. Bright-field images were captured with a NanoZoomer whole-slide imaging system (Hamamatsu Photonics). Semiautomated segmentation of the images was performed with MIPAR Image Analysis Software version 3.0.3 (MIPAR Software LLC) with manual correction to obtain the size of 100 adipocytes.

AT RNA sequencing. Total RNA was isolated from frozen SAAT samples using QIAzol lysis reagent and an RNeasy Mini Kit (QIAGEN) in combination with an RNase-free DNase Set (QIAGEN) as we previously described (80). One SAAT sample from the MHO group was excluded from further analysis because of poor RNA quality attributable to RNA degradation. Library preparation on the remaining samples was performed with total RNA and cDNA fragments sequenced on an Illumina NovaSeq 6000 (Illumina) with all samples sequenced on the same instrument and analyzed during the same run to avoid batch effects. The counts per million (CPM) reads were used to select genes that were significantly $(P<0.005)$ positively and negatively associated with $\mathrm{AT}_{\mathrm{pO}_{2}}$ using Pearson's correlation. Functional enrichment analyses were performed on genes significantly associated with $\mathrm{AT}_{\mathrm{pO}}$ using the Database for Annotation, Visualization and Integrated Discovery (DAVID) Bioinformatics Resources 6.8 (http://david.abcc.ncifcrf.gov/) with Gene Ontology biological process (GO BP) Direct category as we previously described (80). GO terms with a false discovery rate less than 0.01 were considered to be significantly enriched, and redundant GO terms were removed using the REVIGO program (http://revigo.irb. $\mathrm{hr} /$ ). The RNA sequencing data reported in this paper were deposited in the NCBI's Gene Expression Omnibus database (GEO GSE152991).

\section{Statistics}

One-way ANOVA was used to compare subject characteristics and outcome measures among MHL, MHO, and MUO groups, and Fisher's least significant difference procedure was used to identify significant mean differences where appropriate. Polynomial contrasts were performed for selected variables to describe the linear trend from the MHL to the MHO to the MUO group. ANCOVA with age as a covariate was also used to assess the potential importance of the statistically significant difference in mean age between the MHL and MUO groups on the outcomes measures. Relationships between $\mathrm{AT} \mathrm{pO}_{2}$ and hepatic and whole-body insulin sensitivity, AT gene expression, and plasma BCAA, cytokine, and chemokine concentrations were determined using Pearson's correlation coefficient. All statistical tests were 2-sided, and a $P$ value less than 0.05 was considered statistically significant. Data are reported as means \pm SEM unless otherwise noted. Statistical analyses were performed with SPSS (version 25, IBM). Based on the interindividual variability in interstitial $\mathrm{AT}_{\mathrm{pO}}$ we previously reported (5), we estimated that 15 subjects in each group would be needed

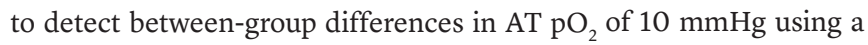
2 -sided test with a power of 0.8 and an $\alpha$ value of 0.05 . These computations were performed with $\mathrm{G}^{*}$ Power 3.1.9.2 (81).

\section{Study approval}

Subjects provided written, informed consent before participating in this study, which was approved by the Human Research Protection Office at Washington University School of Medicine in St. Louis.

\section{Author contributions}

SCB, GIS, and JWB conducted the studies. VC, JY, DM, and JDW performed sample analyses. MJ and BWP supervised the sample analyses. VC, SCB, GIS, JY, JWB, BDK, and SK analyzed the data. VC, SCB, GIS, and SK performed the statistical analyses and wrote the manuscript. SK designed and supervised the studies and obtained funding for the work. SK is the guarantor of this work and, as such, had full access to all the data in the study and takes responsibility for the integrity of the data and the accuracy of the data analysis. All authors critically reviewed and edited the manuscript.

\section{Acknowledgments}

The authors thank Jennifer Shew, Frieda Custodio, and Adewole Okunade for their technical assistance; Janet Winkelmann, Sally Torbitzky, and the nurses of the Clinical Translational Research Unit for their assistance in conducting the studies; and the study subjects for their participation. This study was supported by NIH grants 
K01DK109119， T32HL130357， K01DK116917， R01ES027595, P42ES010337, DK56341 (Nutrition Obesity Research Center), DK20579 (Diabetes Research Center), DK052574 (Digestive Disease Research Center), and UL1TR002345 (Clinical and Translational Science Award); NIH Shared Instrumentation Grants S10RR0227552, S10OD020025, and S10OD026929; and the Foundation for Barnes-Jewish Hospital.
Address correspondence to: Samuel Klein, Center for Human Nutrition, Washington University School of Medicine, 660 South Euclid Avenue, Campus Box 8031, St. Louis, Missouri 63110, USA. Phone: 314.362.8708; Email: sklein@wustl.edu.

SCB's present address is: School of Biological and Health Systems Engineering, Arizona State University, Tempe, Arizona, USA.
1. Klein S, Wadden T, Sugerman HJ. AGA technical review on obesity. Gastroenterology. 2002;123(3):882-932.

2. Bradley D, Magkos F, Klein S. Effects of bariatric surgery on glucose homeostasis and type 2 diabetes. Gastroenterology. 2012;143(4):897-912.

3. Smith GI, Mittendorfer B, Klein S. Metabolically healthy obesity: facts and fantasies. JClin Invest. 2019;129(10):3978-3989.

4. Crewe C, An YA, Scherer PE. The ominous triad of adipose tissue dysfunction: inflammation, fibrosis, and impaired angiogenesis. JClin Invest. 2017;127(1):74-82.

5. Seo JB, et al. Knockdown of Ant 2 reduces adipocyte hypoxia and improves insulin resistance in obesity. Nat Metab. 2019;1(1):86-97.

6. Brestoff JR, Artis D. Immune regulation of metabolic homeostasis in health and disease. Cell. 2015;161(1):146-160.

7. Wallace M, et al. Enzyme promiscuity drives branched-chain fatty acid synthesis in adipose tissues. Nat Chem Biol. 2018;14(11):1021-1031.

8. Herman MA, She P, Peroni OD, Lynch CJ, Kahn $B B$. Adipose tissue branched chain amino acid (BCAA) metabolism modulates circulating BCAA levels. J Biol Chem. 2010;285(15):11348-11356.

9. She P, Van Horn C, Reid T, Hutson SM, Cooney RN, Lynch CJ. Obesity-related elevations in plasma leucine are associated with alterations in enzymes involved in branched-chain amino acid metabolism. Am J Physiol Endocrinol Metab. 2007;293(6):E1552-E1563.

10. White PJ, et al. Branched-chain amino acid restriction in Zucker-fatty rats improves muscle insulin sensitivity by enhancing efficiency of fatty acid oxidation and acyl-glycine export. $\mathrm{Mol}$ Metab. 2016;5(7):538-551.

11. Lo KA, et al. Analysis of in vitro insulin-resistance models and their physiological relevance to in vivo diet-induced adipose insulin resistance. Cell Rep. 2013;5(1):259-270.

12. Pasarica M, et al. Reduced adipose tissue oxygenation in human obesity: evidence for rarefaction, macrophage chemotaxis, and inflammation without an angiogenic response. Diabetes. 2009;58(3):718-725.

13. Pasarica M, Rood J, Ravussin E, Schwarz JM, Smith SR, Redman LM. Reduced oxygenation in human obese adipose tissue is associated with impaired insulin suppression of lipolysis. JClin Endocrinol Metab. 2010;95(8):4052-4055.

14. Lawler HM, Underkofler CM, Kern PA, Erickson C, Bredbeck B, Rasouli N. Adipose tissue hypoxia, inflammation, and fibrosis in obese insulinsensitive and obese insulin-resistant subjects. JClin Endocrinol Metab. 2016;101(4):1422-1428.

15. Kabon B, et al. Obesity decreases perioperative tissue oxygenation. Anesthesiology.
2004;100(2):274-280.

16. Goossens $\mathrm{GH}$, et al. Increased adipose tissue oxygen tension in obese compared with lean men is accompanied by insulin resistance, impaired adipose tissue capillarization, and inflammation. Circulation. 2011;124(1):67-76.

17. Goossens GH, Vogel MAA, Vink RG, Mariman EC, van Baak MA, Blaak EE. Adipose tissue oxygenation is associated with insulin sensitivity independently of adiposity in obese men and women. Diabetes Obes Metab. 2018;20(9):2286-2290.

18. Semenza GL. Regulation of oxygen homeostasis by hypoxia-inducible factor 1. Physiology (Bethesda). 2009;24:97-106.

19. Carmeliet P, Collen D. Molecular basis of angiogenesis. Role of VEGF and VE-cadherin. Ann N Y Acad Sci. 2000;902:249-262.

20. Lee $\mathrm{S}$, et al. Autocrine VEGF signaling is required for vascular homeostasis. Cell. 2007;130(4):691-703.

21. Halberg N, et al. Hypoxia-inducible factor $1 \alpha$ induces fibrosis and insulin resistance in white adipose tissue. Mol Cell Biol. 2009;29(16):4467-4483.

22. Hodson L, Humphreys SM, Karpe F, Frayn KN. Metabolic signatures of human adipose tissue hypoxia in obesity. Diabetes. 2013;62(5):1417-1425.

23. Littleton SW, Tulaimat A. The effects of obesity on lung volumes and oxygenation. Respir Med. 2017;124:15-20.

24. Goossens GH, Jocken JW, Blaak EE, Schiffers PM, Saris WH, van Baak MA. Endocrine role of the renin-angiotensin system in human adipose tissue and muscle: effect of beta-adrenergic stimulation. Hypertension. 2007;49(3):542-547.

25. Jansson PA, Larsson A, Smith U, Lönnroth P. Glycerol production in subcutaneous adipose tissue in lean and obese humans. J Clin Invest. 1992;89(5):1610-1617.

26. Blaak EE, van Baak MA, Kemerink GJ, Pakbiers MT, Heidendal GA, Saris WH. Beta-adrenergic stimulation and abdominal subcutaneous fat blood flow in lean, obese, and reduced-obese subjects. Metab Clin Exp. 1995;44(2):183-187.

27. Helmlinger G, Yuan F, Dellian M, Jain RK. Interstitial $\mathrm{pH}$ and $\mathrm{pO} 2$ gradients in solid tumors in vivo: high-resolution measurements reveal a lack of correlation. Nat Med.1997;3(2):177-182.

28. Hallgren P, Sjöström L, Hedlund H, Lundell L, Olbe L. Influence of age, fat cell weight, and obesity on $\mathrm{O} 2$ consumption of human adipose tissue. Am J Physiol. 1989;256(4 pt 1):E467-E474.

29. Sun K, Halberg N, Khan M, Magalang UJ, Scherer PE. Selective inhibition of hypoxia-inducible factor $1 \alpha$ ameliorates adipose tissue dysfunction. Mol Cell Biol. 2013;33(5):904-917.

30. Yin J, Gao Z, He Q, Zhou D, Guo Z, Ye J. Role of hypoxia in obesity-induced disorders of glucose and lipid metabolism in adipose tissue. Am J Physi- ol Endocrinol Metab. 2009;296(2):E333-E342.

31. Rausch ME, Weisberg S, Vardhana P, Tortoriello DV. Obesity in C57BL/6J mice is characterized by adipose tissue hypoxia and cytotoxic T-cell infiltration. Int JObes (Lond). 2008;32(3):451-463.

32. Regazzetti $C$, et al. Hypoxia decreases insulin signaling pathways in adipocytes. Diabetes. 2009;58(1):95-103.

33. Lee YS, et al. Increased adipocyte $\mathrm{O} 2$ consumption triggers HIF- $1 \alpha$, causing inflammation and insulin resistance in obesity. Cell. 2014;157(6):1339-1352.

34. Liu Y, et al. Hyperbaric oxygen ameliorates insulin sensitivity by increasing GLUT4 expression in skeletal muscle and stimulating UCP1 in brown adipose tissue in T2DM mice. Front Endocrinol (Lausanne). 2020;11:32.

35. Wilkinson D, Chapman IM, Heilbronn LK. Hyperbaric oxygen therapy improves peripheral insulin sensitivity in humans. Diabet Med. 2012;29(8):986-989.

36. Oltmanns KM, et al. Hypoxia causes glucose intolerance in humans. Am J Respir Crit Care Med. 2004;169(11):1231-1237.

37. Fujisaka S, et al. Adipose tissue hypoxia induces inflammatory M1 polarity of macrophages in an HIF-1 $\alpha$-dependent and HIF- $1 \alpha$-independent manner in obese mice. Diabetologia. 2013;56(6):1403-1412.

38. Escribese MM, Casas M, Corbí AL. Influence of low oxygen tensions on macrophage polarization. Immunobiology. 2012;217(12):1233-1240.

39. Sun K, et al. Endotrophin triggers adipose tissue fibrosis and metabolic dysfunction. Nat Commun. 2014;5:3485.

40. Chen B, et al. Hypoxia dysregulates the production of adiponectin and plasminogen activator inhibitor-1 independent of reactive oxygen species in adipocytes. Biochem Biophys Res Commun 2006;341(2):549-556.

41. Hosogai N, et al. Adipose tissue hypoxia in obesity and its impact on adipocytokine dysregulation. Diabetes. 2007;56(4):901-911.

42. Potter van Loon BJ, Kluft C, Radder JK, Blankenstein MA, Meinders AE. The cardiovascular risk factor plasminogen activator inhibitor type 1 is related to insulin resistance. Metab Clin Exp. 1993;42(8):945-949.

43. Festa A, Williams K, Tracy RP, Wagenknecht LE, Haffner SM. Progression of plasminogen activator inhibitor-1 and fibrinogen levels in relation to incident type 2 diabetes. Circulation. 2006;113(14):1753-1759.

44. Meigs JB, et al. Hemostatic markers of endothelial dysfunction and risk of incident type 2 diabetes: the Framingham Offspring Study. Diabetes. 2006;55(2):530-537.

45. Ma LJ, et al. Prevention of obesity and insulin 
resistance in mice lacking plasminogen activator inhibitor 1. Diabetes. 2004;53(2):336-346.

46. Liang X, et al. Plasminogen activator inhibitor-1 modulates adipocyte differentiation. Am J Physiol Endocrinol Metab. 2006;290(1):E103-E113.

47. Lijnen HR, Alessi MC, Van Hoef B, Collen D, Juhan-Vague I. On the role of plasminogen activator inhibitor-1 in adipose tissue development and insulin resistance in mice. J Thromb Haemost. 2005;3(6):1174-1179.

48. Ying $\mathrm{W}$, et al. Adipose tissue macrophagederived exosomal miRNAs can modulate in vivo and in vitro insulin sensitivity. Cell. 2017;171(2):372-384.e12.

49. Newgard CB, et al. A branched-chain amino acid-related metabolic signature that differentiates obese and lean humans and contributes to insulin resistance. Cell Metab. 2009;9(4):311-326.

50. Wang TJ, et al. Metabolite profiles and the risk of developing diabetes. Nat Med.2011;17(4):448-453.

51. Guasch-Ferré M, et al. Metabolomics in prediabetes and diabetes: a systematic review and meta-analysis. Diabetes Care. 2016;39(5):833-846.

52. Wang Q, Holmes MV, Davey Smith G, AlaKorpela M. Genetic support for a causal role of insulin resistance on circulating branched-chain amino acids and inflammation. Diabetes Care. 2017;40(12):1779-1786.

53. Magkos F, et al. Effect of Roux-en-Y gastric bypass and laparoscopic adjustable gastric banding on branched-chain amino acid metabolism. Diabetes. 2013;62(8):2757-2761.

54. Shah SH, et al. Branched-chain amino acid levels are associated with improvement in insulin resistance with weight loss. Diabetologia. 2012;55(2):321-330.

55. White PJ, Newgard CB. Branched-chain amino acids in disease. Science. 2019;363(6427):582-583.

56. Tzatsos A, Kandror KV. Nutrients suppress phosphatidylinositol 3-kinase/Akt signaling via raptor-dependent mTOR-mediated insulin receptor substrate 1 phosphorylation. Mol Cell Biol. 2006;26(1):63-76.

57. Patti ME, Brambilla E, Luzi L, Landaker EJ, Kahn CR. Bidirectional modulation of insulin action by amino acids. JClin Invest. 1998;101(7):1519-1529.

58. Jang $C$, et al. A branched-chain amino acid metabolite drives vascular fatty acid transport and causes insulin resistance. Nat Med.
2016;22(4):421-426.

59. Harris LLS, et al. Alterations in 3-hydroxyisobutyrate and FGF21 metabolism are associated with protein ingestion-induced insulin resistance. Diabetes. 2017;66(7):1871-1878.

60 . Koumenis C, et al. Regulation of protein synthesis by hypoxia via activation of the endoplasmic reticulum kinase PERK and phosphorylation of the translation initiation factor eIF2alpha. $\mathrm{Mol}$ Cell Biol. 2002;22(21):7405-7416.

61. Arsham AM, Howell JJ, Simon MC. A novel hypoxia-inducible factor-independent hypoxic response regulating mammalian target of rapamycin and its targets. J Biol Chem. 2003;278(32):29655-29660.

62. Liu L, Cash TP, Jones RG, Keith B, Thompson CB, Simon MC. Hypoxia-induced energy stress regulates mRNA translation and cell growth. Mol Cell. 2006;21(4):521-531.

63. Glockner JF, Norby SW, Swartz HM. Simultaneous measurement of intracellular and extracellular oxygen concentrations using a nitroxide-liposome system. Magn Reson Med.1993;29(1):12-18.

64. Semenza GL, Wang GL. A nuclear factor induced by hypoxia via de novo protein synthesis binds to the human erythropoietin gene enhancer at a site required for transcriptional activation. Mol Cell Biol. 1992;12(12):5447-5454.

65. Brahimi-Horn C, Mazure N, Pouysségur J. Signalling via the hypoxia-inducible factor-1alpha requires multiple posttranslational modifications. Cell Signal. 2005;17(1):1-9.

66. Ye J, Gao Z, Yin J, He Q. Hypoxia is a potential risk factor for chronic inflammation and adiponectin reduction in adipose tissue of ob/ob and dietary obese mice. Am J Physiol Endocrinol Metab. 2007;293(4):E1118-E1128.

67. Lee KY, Gesta S, Boucher J, Wang XL, Kahn CR. The differential role of Hif1 $\beta$ /Arnt and the hypoxic response in adipose function, fibrosis, and inflammation. Cell Metab. 2011;14(4):491-503.

68. Jiang $C$, et al. Disruption of hypoxia-inducible factor 1 in adipocytes improves insulin sensitivity and decreases adiposity in high-fat diet-fed mice. Diabetes. 2011;60(10):2484-2495.

69. Kietzmann T, Roth U, Jungermann K. Induction of the plasminogen activator inhibitor-1 gene expression by mild hypoxia via a hypoxia response element binding the hypoxia-inducible factor- 1 in rat hepatocytes. Blood. 1999;94(12):4177-4185.

70. Higgins DF, Biju MP, Akai Y, Wutz A, Johnson RS, Haase VH. Hypoxic induction of Ctgf is directly mediated by Hif-1. Am J Physiol Renal Physiol. 2004;287(6):F1223-F1232.

71. Mifflin MD, St Jeor ST, Hill LA, Scott BJ, Daugherty SA, Koh YO. A new predictive equation for resting energy expenditure in healthy individuals. Am J Clin Nutr. 1990;51(2):241-247.

72. Klein S, et al. Absence of an effect of liposuction on insulin action and risk factors for coronary heart disease. NEnglJMed. 2004;350(25):2549-2557.

73. Morozov D, Quirk JD, Beeman SC. Toward noninvasive quantification of adipose tissue oxygenation with MRI. Int JObes (Lond). 2020;44(8):1776-1783.

74. Griffiths JR, Robinson SP. The OxyLite: a fibre-optic oxygen sensor. Br JRadiol. 1999;72(859):627-630.

75. Smith GI, et al. Insulin resistance drives hepatic de novo lipogenesis in nonalcoholic fatty liver disease. JClin Invest. 2020;130 (3):1453-1460.

76. Matthews DR, Hosker JP, Rudenski AS, Naylor BA, Treacher DF, Turner RC. Homeostasis model assessment: insulin resistance and betacell function from fasting plasma glucose and insulin concentrations in man. Diabetologia. 1985;28(7):412-419.

77. Kantz ED, Tiwari S, Watrous JD, Cheng S, Jain M. Deep neural networks for classification of LC-MS spectral peaks. Anal Chem. 2019;91(19):12407-12413.

78. Mittendorfer B, Horowitz JF, Klein S. Gender differences in lipid and glucose kinetics during short-term fasting. Am J Physiol Endocrinol Metab. 2001;281(6):E1333-E1339.

79. Korenblat KM, Fabbrini E, Mohammed BS, Klein S. Liver, muscle, and adipose tissue insulin action is directly related to intrahepatic triglyceride content in obese subjects. Gastroenterology. 2008;134(5):1369-1375.

80. Yamaguchi S, et al. Adipose tissue $\mathrm{NAD}^{+}$ biosynthesis is required for regulating adaptive thermogenesis and whole-body energy homeostasis in mice. Proc Natl Acad Sci U S A. 2019;116(47):23822-23828.

81. Faul F, Erdfelder E, Lang AG, Buchner A. G*Power 3: a flexible statistical power analysis program for the social, behavioral, and biomedical sciences. Behav Res Methods. 2007;39(2):175-191. 